\title{
Green Economy: Challenges of Sustainable Consumption and Production in Ethiopia
}

\author{
Belay Addisu \\ Dire Dawa University, Department of Marketing Management, Dire Dawa, Ethiopia
}

(Belay A.)

\begin{abstract}
Sustainability issues became the most common agenda of several countries around the world, due to the three nucleolus factors such as social, economic and environment. Sustainable consumption and production is among the fundamental concern of the UN SDGs. Though, Ethiopia's manufacturing sector is at its infant stage, few industries located around urban areas, are releasing their waste into the river system. Like many other African countries, Ethiopia is suffering from climate change and environmental pollution. Cognizant of this, the Ethiopian government planned to transform the country into a middle income category with zero carbon emission by 2025 by executing the GTP and CRGE initiative. However, successful implementation of the program confronted several challenges. Thus, the aim of this study is to identify major bottlenecks related to SCP and to point out possible ways to achieve a green economy trajectory in Ethiopia. The current research paper is a qualitative study in to the SCP. Secondary data from peer-reviewed reputable journals, UN SDG 12 reports, country wide analysis on green economy, FDRE SDG reports, news release, website of Ministry of Environment, Forest \& Climate Change (MEFCC) and sustainability stakeholders report have been collected and analyzed. A semi-structured interview was carried out with MEFCC office personnel. Loose environmental policy enforcement at national, regional and local level, complexity in organizing SMEs structure for green, lack of knowledge and awareness regarding the impact and benefits of green economy among private industries, poor incentive package for private firms to promote environmental activities and support green economy and insufficient, unreliable and irresponsible production are among the major environmental bottlenecks that Ethiopia is facing currently.
\end{abstract}

Keywords: Sustainable consumption and production (SCP), CRGE (Climate Resilience Green Economy), Sustainable Development Goals, Green Economy

DOI: $10.7176 / J E S D / 10-1-05$

\section{Introduction}

Sustainability issues became the most common agenda of several countries around the world, due to the three nucleolus factors such as social, economic and environment. ${ }^{[1]}$ Sustainable consumption and production is among the fundamental concern of the UN Sustainable Development Goal (Goal 12) where consumers, firms and government are the foremost players. Significant amount of research works and debates have been made during the last decade by academicians, strategy and policy makers, ecologists, government and civic societies with regarding SCP. ${ }^{[2]}$

A change in climate and global warming enlarges the concern and participation of several stakeholders over green problems in the past decades. Since the early 1960s, several academicians and professionals throughout the world became environmental conscious and have raised environmental issues in various conferences. This act is now a common practice mainly after the Copenhagen Climate Conference 2009. Intense debates and discussions are currently undergoing across the globe on how to mitigate the devastating impact of pollution and degradation. Since the early 1970s, a considerable number of studies have been carried out on consumer green purchase behavior. Several buying behavior variables such as attitude, values, beliefs and knowledge and demographic variables are revealed as a prime factors driving consumer purchase behavior of green products. ${ }^{[3]}$ Nevertheless, there have been very few researches conducted on ecological products buying behavior in Ethiopia compared with western nations.

According to CSA ${ }^{[4]}$ Ethiopia is the second largest populated country in Africa with a population of more than 90 million and its natural resource is highly depleted and hence it requires a great deal of attention for the right sense of balance between green consumption and environment protection. Besides, several African countries including Ethiopia by considering the undesirable ecological impact of environmentally unfriendly products, have designed regulations which highly ban the production and use of plastic packages. However, the policy is not implemented sincerely. Statistical evidences ascertain that consumers' awareness level towards green products and firms' environmental alertness has been changed and they are more conscious. Though it is difficult to generalize but the issue has not been given too much attention in developing countries. Thus, marketing is a very powerful weapon to be implemented to enhance consumers' awareness and measure their preference for ecological products.

The global environment is also significantly affected by production activities such as agriculture, 
manufacturing and extraction of natural resources. Innovation and new manufacturing practice helped industrially advanced countries in reducing the undesirable environmental impact. However, sustainability issues coupled with economic growth exacerbate the challenge of developing countries. ${ }^{[5]}$

Overseas companies investing in emerging markets are encountered with major challenges in designing winning marketing techniques, due to short of information about consumers' green buying behavior ${ }^{[6]}$ Hence, in depth understanding of green consumption behavior in these markets are required. Nowadays, countries speedy growth in economy coupled with consumers' over-consumption of natural resources leads to environmental destruction. ${ }^{[7]}$ Concern for the environment and successive efforts of environmentalists to enhance community's awareness over the negative impact on the environment has become a nucleus global topic. ${ }^{[8]}$

\section{Problem Statement}

Sustainability is satisfying the current need of consumption and production without compromising the future generations needs. ${ }^{[9]}$ Consumption as usual presents a threat to the natural resource on which we all depend on at local, regional and global level. This challenge will be overblown as the world population increases; hence, more energy, material and services from the ecosystem are required which in turn overwhelm the ecosystem. ${ }^{[10]}$ Business can play an imperative role in combating this challenge in a more sustainable pattern.

Very recently, businesses, governments and NGOs are highly participating on how production and consumption be made in a more sustainable path. Preserving and improving the environment we live in has become the center of discussion among scholars, policy makers and environmentalists because the issue greatly affects the welfare of the people and the development of the economy at large. According to Yared [11] desertification, greenhouse effect and global warming, Tran's boundary movements of hazardous wastes and their disposal, global loss of biodiversity, air pollution, hazardous chemicals, climate change and deforestation are among the prevailing series global environmental problems in Africa in general and in Ethiopia in particular.

Though, Ethiopia's manufacturing sector is at its infant stage, few industries located around urban areas, are releasing their waste into the river system, this is especially true in the capital Addis Ababa. Poor waste management practice, unsatisfactory environmental regulation system and implementation, lack of environmental awareness and concern and weak NGO's participation are among the major environmental bottlenecks that Ethiopia is facing currently. ${ }^{[11]}$ Delinking the eco-system with the economic development, with the aim of operating within the limited resource the earth has, is the foremost bottleneck for realizing sustainable consumption and production. ${ }^{[12]}$

Like many other African countries, Ethiopia is suffering from climate change and environmental pollution. Cognizant of this, the Ethiopian government planned to transform the country into a middle income category with zero carbon emission by 2025 by executing the GTP and CRGE (Climate Resilience Green Economy) approach. However, successful implementation of the initiative confronted several challenges. Thus, this qualitative research aims at answering the following research questions.

\subsection{Research Question}

1. What are the bottlenecks of sustainable consumption and production in Ethiopia?

2. How can the challenges of sustainable issues be handled?

\section{Purpose of the study}

The aim of this study is to identify major bottlenecks related to sustainable consumption and production and to point out possible ways to achieve a sustainable consumption and production path in Ethiopia.

\section{Literature Review}

\subsection{What is sustainable consumption and Production?}

As per the earliest international gatherings at Oslo symposium on the issue sustainability, a working definition of sustainable consumption is proposed as:

"the use of goods and services that respond to basic needs and bring a better quality of life while minimizing the use of natural resources, toxic materials and emissions of waste and pollutants over the life cycle, so as not to jeopardize the needs of future generations. ${ }^{[13]}$

Lebel et al ${ }^{[14]}$ described that this definition is very broad with diverse meaning such as utilizing less power intensive resources, wise consumption of natural resources, energy conservation and buying superior quality products having extended life spans. Jackson ${ }^{[15]}$ views this from cultural and economic perspective. From cultural standpoint, it is a move away from the traditional consumerist culture to a more environment oriented life style and from an economic side; it is shifting the economy from producing environmentally unfriendly consumer products towards following a more sustainable production path. Sustainable consumption is a way of consuming differently and efficiently which in turn enables better standard of living and improved quality of life, but it doesn't mean less consumption. 
Sustainable production can be defined as the process of creating goods and services by using systems that are non-polluting, energy conserving, natural resource preserving and making no harm to the employees, community and society while bringing creative benefits to all stakeholders. ${ }^{[16]}$ According to Deloitte ${ }^{[17]}$ though more than 35 countries worldwide have designed national sustainable consumption and production strategies and policies, their practical commitment in reducing the usage of natural resources and environmental degradation related with consumption is almost none. Individual companies and business leaders can better position themselves by introducing a business model and innovative products that is centered on environmental friendly production and consumption.

World Economic Forum and Deloitte ${ }^{[18]}$ reveals that consumers environmental concern in both developing and developed countries has shown tremendous growth and in spite of economic collapse in varies countries the issue of sustainability and the participation of stakeholders on the agenda remains high. The empirical finding indicated that price, quality and convenience are the dominant parameters consumers consider for purchase than dictated by sustainability issues. ${ }^{[17]}$ On the contrary, Sylvia et al ${ }^{[20]}$ state that consumption patterns in advanced and developing nations are unsustainable. People consume energy and raw-materials in unfair way and disposal of hazardous wastes and consumption of renewable materials became rise unsustainably.

\subsection{Contribution of SCP to meeting SDGs}

Realizing the UN's SDG 12 demands countries to demonstrate strong commitment in efficient utilization of natural resources. Sustainable consumption and production is multi-dimensional and it involves stakeholders such as governments, businesses, societies and consumers who contribute to the quality of the environment through wise utilization of natural resources, reducing wastes and efficient production of goods and services. The Johannesburg summit which was held in 2002 called for the establishment of a 10 year framework of programmes with the aim of backing national and regional schemes to hasten the trajectory to SCP. ${ }^{[20]}$ Despite the objective of boosting the economic development and reducing poverty, SCP is considered as the key to realize the SDGs. Designing appropriate SCP strategies enables countries to meet other national development programmes. Table 1 explains the contribution of SCP for the realization of the rest of SDGs.

Table 1: Contribution of SCP for the achievement of the SDGs

SDGs

Goal 1: No Poverty

Goal 2: Zero Hunger
Consumers increased demand for green products will results in more number of ecology concerned manufacturers with a new market entry, this will create job opportunity which in turn accelerates the nation's economy.

Countries can improve their land productivity and enlarge access to food by optimum management and utilization of natural resources and farming land via green economy practices. People can achieve their fundamental needs (water, energy and food) if there is clean and resource efficient services.

Goal 3: Good health The health of pregnant women can be improved if there is more efficient energy, water and well-being service and adequate, clean and more efficient energy

Goal 4: Quality Commencing environmental awareness creation scheme and resource efficient Education consumption and production issues at school's curriculum will positively shape the behavior of young generations and their family.

Goal 5: Gender Women and children in developing countries fetch water and collect fuel wood, which equality creates a burden on them and reduces the time spent for education and revenue generation activities. Hence, provision of sustainable \& resource wise energy will improve the situation.

Goal 6: Clean water Better and improved management of natural resources such as safeguarding water and sanitation resources and designing sanitary techniques and sustainable nutrition projects could enable to lessen the undesirable impact and improve the public health. Provision of sanitized water, sustainable energy and responsible resource utilization will sharply diminish the occurrence of diseases caused by waster and severe respiratory infection.

Goal 7: Affordable Conscious deployment of natural resources throughout their life cycle yields enhanced and clear energy productivity and reduced energy cost and introduction of new recycle technology to promote enhanced, reasonable and sustainable energy can be achieved when the responsible consumption and Production initiatives are realized.

Goal 8: Decent work Sustainable and responsible consumption and efficient utilization of natural resources and economic growth is a base for global economic growth and firm's productivity.

Goal :9 Industry, Efficient production and consumption will results in enhanced infrastructural innovation and development, innovation and improved trajectory to the development of infrastructure 
Goal 10: Reduced Wise and cognizant utilization of resources among consumers and producers across inequality countries will ensure equitable distribution of resources hence, income disparity and migration in developing countries will be reduced.

Goal 11: Sustainable Waste management, clean and polluted free environment which are the goal of SCP cities \& communities will contribute extensively to the achievement of sustainable urban population and cities.

Goal 13: Climate Efficient production and consumption and raised environmental awareness and reaction concern among consumers, academicians and businesses are the weapons to fight a change in climate and its negative impact.

Goal 14: Life below Depletion of under water resources caused by over-exploitation of marine life by water businesses and misuse and reckless disposal of products by consumers will have a devastating impact, hence, eco-friendly production, green consumption and conservation of natural resources which are the aim of SCP, will bring change to the prevailing condition.

Goal 15: Life on land Manufacturers where their source of input is natural resources are highly degrading the eco-system, create desertification, and affecting the global biodiversity. Thus, the benefits of natural resources will be enjoyed by producing sustainably and responsibly

Goal 17: Partnership Cooperation and collaboration established at the international level with stakeholders for the goals to enhance SCP will assist the effort of realizing international initiatives and incite Source: Adapted from UNEP ${ }^{[21]}$ efficient resource deployment.

\subsection{Sustainable Consumption and Production Pattern in Ethiopia}

The nucleus of SCP is efficiency-i.e. enhancing the living standard of the citizen by producing better with minimum resource utilization. UNDP under its sustainable development goal 12 defined SCP as a wise use of both resource and energy, promoting eco-friendly infrastructure and ensuring everyone to have access to fundamental services, green and enhanced standard of living for all. Its execution demands all stakeholders' to tradeoff their short term environmental, economic and social interest with the future sustainable development of the world at large. Though, the government of Ethiopia tried to address the issue of environment such as soil, water and air pollution in its policies, the consumption of material and natural resource remains high.

Ethiopia currently is pursuing a green economy trajectory along with economic development. Consequently, with the aim of mitigating the negative impact of climate change and promoting green growth, Ethiopia has designed a Climate-Resilience Green Economy (CRGE) strategy, and so far more than sixty initiatives that could assist the economic and sustainable development program have been scrutinized and prioritized. The strategy is expected to bring not only environmental benefits but also social and economic advantages. ${ }^{[22]}$ The development of green economy is based on four pillars;

a) Improving crop and livestock production practices to increase food yields, leading to food security and stable farmer income, while reducing emissions;

b) Protecting and re-establishing forests for their economic and ecosystem services, including their operation as carbon stocks;

c) Expanding electric power generation from renewable sources of energy fivefold over the next five years for markets at home and in neighboring countries; and

d) Leapfrogging to modern and energy-efficient technologies in transport, industry, and buildings.

In line with this the government of Ethiopia synergized green economy with structural transformation strategies by linking long term green vision with short and medium term targets. Apparently, to implement the green economy trajectory four potential areas have been identified i.e. hydropower development, rural cooking technologies, the livestock value chain, and forestry development. This strategy results in pressing economic growth and low carbon emission in the country. ${ }^{[23]}$

\section{Research Methodology}

The current research paper is a qualitative study in to the green economy and SCP. Hence, with the view of investigating the research objective both primary and secondary data have been collected and analyzed. According to Ader ${ }^{[24]}$ there are no independent or dependant variables involved in a qualitative study as a qualitative strategy is not experimental in nature. Saunders ${ }^{[25]}$ states that when it comes to conceptual research, it is important to review previously done researches on the same subject matter. Primarily, the researcher adopted a systematic literature review strategy to gather literatures on sustainable consumption and production (SCP) from peer-reviewed reputable journals, UN SDG 12 reports, country wide analysis on green economy, FDRE's SDG reports, news release, website of Ministry of Environment, Forest \& Climate Change (MEFCC) and sustainability stakeholders report and others. Well reputable journals from developing and developed countries 
such as Taylor \& Francis, Elsevier, Emerald, Springer and other sustainability journals were used to collect data regarding green economy and SCP. Out of the total articles reviewed, more than $85 \%$ of them are published during the last fifteen years; this indicates how much concern given to sustainable development. In order to beef up the study and to gain depth insight into the topic SCP, a semi-structured interview was carried out with MEFCC office personnel.

\section{Empirical Review and Discussion Green Movement in Ethiopia}

Several strategic and institutional structures have been designed in Ethiopia in the effort of managing the environment. The constitution of Ethiopia integrates quite a few articles pertinent to the protection and sustainability of the environment; article 43,44,89,91 and 92 are the manifestation of this, they all highly emphasized on ensuring sustainable development. Like any other African countries, Ethiopia is also facing the adverse impact of climate change. These brought the need and the opportunity to adopt a new and sustainable development model. In line with this, the FDRE has instigated the Climate-Resilient Green Economy (CRGE) program with the aim of realizing the country's vision of reaching middle income class at 2025 . The office in charge of environmental agendas--the Ministry of Environment, Forest and Climate Change in collaboration with the Ethiopian Development Research Institute, has designed a strategy to achieve green economy by identifying possible opportunities that the country can attain its ambition while reducing the emission of greenhouse gas. International and domestic development partners have been invited to actively engage in the achievement of the strategy. According to the recent World Bank's report, the adverse effect of climate change will shrink Ethiopia's GDP by between 0.5 to $2.5 \%$ every year and due to the detrimental effect of climate change, the total GDP potential that Ethiopia's could attain will reduce by half in 25 years time unless a move toward climate resilience is effectively implemented. To this effect, the ministry of environment, forest and climate change immensely participates in addressing climate challenges by initiating and coordinating international environment agreements according to Proclamation No. 916/2015. In response to SCP, Ethiopia ratified several multi-lateral agreements centered on environment particularly on the areas of biodiversity, Ozone and Climate and Hazardous Waste and Chemicals. ${ }^{[1]}$

UNDP Ethiopia ${ }^{[2]}$ announces that the UNDP in collaboration with the government of Ethiopia have commenced a program that will foster the synergy between urban waste management and greening 6 selected cities in the country. As stated by the state Ministry of Finance and Economic Cooperation (MoFEC), towns in Ethiopia are encountered with the problem of handling solid waste value chain and executing and maintaining city's green infrastructure aggravate the challenge.

\section{Challenges in Green Economy and Sustainable Consumption and Production in Ethiopia}

Industrialization has been considered as a key trajectory for the realization of Ethiopia's GTP II. On the contrary, our country is suffering from sustainability crisis and climate change. Hence, unless bounded by regulation, development of industries may cause environmental pollution such as air, water, toxic and several harmful environmental impacts. ${ }^{[31]}$ To tackle the challenge, Ethiopia has designed a green economy approach by leapfrogging up to date technologies and green industrial parks that has waste treatment and energy wise technologies while maintaining the economic development path underway.

As per SDG index and Dashboards-Global report, Ethiopia is rated as the least $11^{\text {th }}$ and $20^{\text {th }}$ country in terms of wastewater treatment and municipal solid waste respectively. ${ }^{[32]} \mathrm{SCP}$ agendas in developing economies are very serious and the issue ranges from efficient utilization of resources to the use of revolutionary technology for the wellbeing of humankind. ${ }^{[33]}$ The subject of sustainable production encompasses both manufacturing and farming. According to Barber ${ }^{[34]}$ lack of government keenness and resistance in implementing SCP policies at the national level are the fundamental reasons for poor progress in the sustainability issues as per the United Nations report. The major hindrance to the prevailing SCP is related with availability of energy, depletion of resources and degradation of the environment. ${ }^{[35]}$ As evidenced from empirical research works ${ }^{[36]}$ food, housing, energy and transportation are the primary environmental destructions observed in Europe and other advanced countries.

The World Business Council on Sustainable Development ${ }^{[37]}$ reveled that consumers concern and knowledge towards the environment have been changed positively, however, their interest failed to turn into sustainable consumption of green products. Availability, product performance, affordability, convenience, skepticism, force of habit and conflicting priorities are the major factors for not becoming a truly green consumer. David et al ${ }^{[38]}$ as cited from World Bank ${ }^{[39]}$ the two most important reasons ranked by consumers for

\footnotetext{
${ }^{1}$ Ministry of Environment, Forest and Climate Change, Ethiopia (MEFCC) (2017), Available at http://mefcc.gov.et/about-us/, Accessed on $[07 / 06 / 2018]$

${ }^{2}$ UNDP Ethiopia (2018), Available at http://www.et.undp.org/content/ethiopia/en/home/presscenter/pressreleases/2017/02/22/ethiopialaunches-new-sustainable-intervention-for-green-cities-development-.html Accessed on [15/06/2018]
} 
not highly participating in ecological products consumption are lose of trust in firms and a belief that a single person action has no contribution unless a massive measure is taken by government and businesses. To make consumption more sustainable, government and businesses need to change the system in which they are operating.

The major bottlenecks for Ethiopia not to realize UN's Sustainable Development Goal 12 are:

a) Poor education and lack of awareness and knowledge with regard to the pay offs of SCP

b) Absence of government's solid commitment in enforcing policies

c) Inadequate institutional performance evaluation and monitoring mechanism

d) Inept manpower and technology including incompetent capacity for innovation and new product development

e) Huge dependence on outdated equipment and unaware of flourishing eco-friendly technologies

f) Unsatisfactory number of SCP supporting government and non-government institutions

g) Lack of research and development centers and inadequate number of researches on SCP

h) Poor record of data on air, water and soil pollution and the utilization of natural resources

i) Poor collaboration of the international community on sustainable agendas

Ethiopian Environment Research Institute ${ }^{[3]}$ ensures that bottlenecks of green economy are multi dimensional, which are caused by challenges including institutions, information, incentive and private investors. Loose environmental policy enforcement at national, regional and local level, complexity in organizing SMEs structure for green, lack of knowledge and awareness regarding the impact and benefits of green economy among private industries, poor incentive package for private firms to promote environmental activities and support green economy and insufficient, unreliable and irresponsible production are among the major environmental bottlenecks that Ethiopia is facing currently. Lack of active and greater engagement of the general public, shallow understanding of consumer's behavior and poor collaboration among stakeholders on combating environmental impacts are also major challenges in achieving sustainability Ethiopia.

The interview made with Dire Dawa, Environment, Forest and Climate Change (EFCC) office director reveals that, Ethiopia has sound legal framework to take care of environmental issues; however, the major challenges are loose collaboration and communication among sectoral offices and ministries at federal, regional and local levels, poor policy implementation enforcement and inadequate fund raising from external environmental funding institutions. In fact, some laws need to be modified and updated since they lack execution regulation and policy. Climate change, environmental pollution and sustainable development are a global problem and it requires the participation of many stakeholders. As reported by the Ministry of Environment, Forest and Climate Change of Ethiopia, the sector is frequently suffering from insufficient funding and incompetent professional in the area. Moreover, reluctance of the public in actively participating in managing environmental issues at the grass root level has been considered as a major hindrance. Bottom-up participation is central in bringing the expected outcome and executing the country's environmental policy. Though, communities and officials at the local and regional level can make a positive change in handling environmental challenges, their participation and engagement is highly limited due to inadequate funds, following centrally decided priorities and lack of full authorization.

\section{The challenge of balancing economic development and sustainable development trajectory}

Ethiopia's economic growth is expected to mounting up as one of the world's fastest growing over the coming years. The country plan of achieving a middle income status prior to 2025 demands huge emphasis on agricultural effectiveness, heightening the manufacturing base and promoting the export sector. Quite the reverse, Ethiopia as a member of various international climate negotiations, is conscious about climate change and playing a very decisive role in realizing green economy. As per All Africa, ${ }^{[1]}$ Ethiopia has long recognized the connection between economic path and climate change. Balancing economic and sustainable development path is the central challenge of achieving Ethiopia's green economy. Achieving the country's ambition before 2030 at the cost of the devastating impact of climate change as observed all around the world will undermine the long term development of Ethiopia. The contribution of Ethiopia to greenhouse gas emissions is very limited as rated on a global scale; nevertheless, the estimated pressure of conventional economic development on the environment indisputably heighten the problem as practically observed in the globe. FDRE report ${ }^{[22]}$ reveals that as per the prevailing scenario, Greenhouse Gas emission (GHG) would accelerate by double from $150 \mathrm{Mt} \mathrm{CO} 2 \mathrm{e}$ in 2010 to $400 \mathrm{Mt} \mathrm{CO} 2 \mathrm{e}$ in 2030 and resource limitations and technological obsolesce will be in question. Likewise, financial constraints will cause a pressure on the country's economy. On an individual level releases are expected to boost by 50 percent to $3.0 \mathrm{t} \mathrm{CO} 2 \mathrm{e}$, this will surpass the goal of maintaining release between $1 \mathrm{t}$ and $2 \mathrm{t}$ per head to reduce the undesirable impact of climate change. Of the total GHG emissions, the

\footnotetext{
${ }^{1}$ All Africa (2018), The Ethiopian Herald, Ethiopia: Country's Green Economy - Making Sustainable Development a Reality, Available at: https://allafrica.com/stories/201506250731.html Accessed on [15/06/2018]
} 
contribution of agriculture and forestry accounts more than 85 percent whereas the power, transport, industry and buildings contribute to the remaining percentage.

The issue of green in developing countries has two wings; economic and sustainable path. Pursuing economic development to eradicate poverty and promoting the living standard by avoiding unsustainable and inefficient resource utilization has been the center of discussion these days among developing countries. Designing a systematic link between the short-term approach (boosting country's income and job creation through investment) and the long-term perspective (achieving sustainable development goals through wise and efficient resource consumption) should be in place to realization green economy in Ethiopia.

\section{The role of government}

The commitment and determination of the government of Ethiopia is very imperative for successful execution of the CRGE program and the realization of several green multi-lateral agreements. Undeniably the backing provided by UNEP alongside the financial provision by the World Bank and other interested development partners were significant for what has been recorded so far in sustainable development in Ethiopia. The government should maintain and nurture its relationship with domestic and international development partners such as African Union Commission, ECA and UNEP, World Bank and other stakeholders.

Mulugeta Mengistu, advisor and director of climate change at the office of the Prime Minister, very recently addressed the issue of the implementation of Ethiopia's green economy strategy by stating that:

"If we look at the experience of the Western countries, when they grow their economy by 1\% they almost grow their emission by the same amount. But, what we are planning to do is, we were convinced that we can grow our economy and we can become a middle income country without increasing our annual emission "11]

The central objective of the strategy was to maintain the GHG emission as it was while fostering the economic development path. However, a developing country aspiring to boost its development would find it hard to realize its plan. As per the report, Ethiopia's annual CO2 emission was 150 millions of tons in 2010 and if the country aspires to continue its economic development conventionally the annual emission would rise to 400 million tons of $\mathrm{CO} 2$. Thus, appropriate strategy should be in place to ensure that climate change and economic development are going hand in hand. The government of Ethiopia should develop a wide range of compulsory and voluntary policy tools to promote firms to adopt sustainable production practices. Legal frameworks can also be designed so that stakeholders can operate sustainably in the society. These legal instruments include customer protection regulation, extensive manufacturer responsibility, product standards and liability procedures, public procurement guidelines and compulsory operating reporting requirements.

\section{Research and Education for SCP}

The foundation for solid establishment of SCP is enhanced awareness, knowledge, attitude and concern of the general population with regard to the benefits of SCP and the adverse effect of unsustainable consumption and production. Education and communication are essential instruments in raising awareness and enlightening the seriousness of environment deterioration among Ethiopian people. Both long-term educational programs and short-term intensive community oriented awareness creation movements highly focusing on consumers, business organizations, NGO's, funding institutions and environmentalists. A survey made by UNESCO (2014), showed that farmers in 10 African countries reduced their climate irresponsibility by $1.6 \%$ every year after rigor research and education. Daniel ${ }^{[40]}$ as cited from UNCSD ${ }^{[13]}$ indicates education, awareness creation campaign and capacity building activities are the major focus of numerous countries governments, NGO's, UN organizations and other stakeholders as a remedy for the prevailing bottlenecks of climate change, biodiversity loss and sustainable production and consumption.

\section{Lessons for Ethiopia from other experiences in Sustainable Consumption and Production}

Green growth is a necessity for Ethiopia to apprehend ecological problems which causes poverty for millions of Ethiopians and provides an opportunity to take advantage of the country's vast energy potential. ${ }^{[41]}$ Despite the increasing economic growth and improved attention to provided to sustainable development, there are a lot of lessons that Ethiopia should learn from other emerging and advanced nations regarding SCP.

Green growth provides both long and short term benefits and opportunities for developing countries. Ecology service incentive package of Costa Rica, natural resource reservation scheme of Azerbaijan and community centered institutions designed to encourage agricultural waste management program of Bangladesh exhibit economic development opportunities from investing on efficient resource utilization and sustainable sectoral development. A cook stove manufactured by Toyola in Ghana, conserves energy by 40 percent than the usual model. Cambodia's biomass energy generated from agricultural residue can preserves the COC2 emission

\footnotetext{
1 Tesfagebriel T. (2018) Implementation of Ethiopia's Green Economy Strategy: an example to learn from Available at: https://www.awrambatimes.com/?p=16572 Accessed on [17/06/2018]
} 
by more than 9,000 tons per annum, reduces the cost as little as half that of grid electricity and avoid the requirement of three million liters of fuel. Well-established regulatory policy structure and framework of Jamaica helped the country to fully execute the exploitation of energy from renewable innovations such as wind, solar and biomass has saved Jamaica's foreign exchange which would have to be spent for the import of fuel. ${ }^{[1]}$ A community based institution - WesteConcern, designed a waste management scheme in Bangladesh, which is transforming street natural waste into farming manure which in turn eliminate the import of chemical fertilizer and saves the country's foreign currency by 1.24 million dollar from 2001-2006. Similarly, the local government of Nairobi in collaboration with the federations of slum dwellers has shown a remarkable commitment in enhancing the living standard of the population by crafting and building eco-friendly houses and infrastructures, which is inexpensive and superior in quality. ${ }^{[43]}$ According to UN's report ${ }^{[5]}$ the Korean government initiates several reforms regarding environmental protection schemes such as a framework for green government purchasing, commencement of eco-label strategy, creation of green products awareness creation platform and country wide virtual monitoring mechanism.

\section{Recommended Measures to Handle Sustainable Consumption and Production (SCP) in Ethiopia}

Ethiopia has been experiencing severe environmental challenges in the past decades. Inconsistent rainfall brought drought and flood which severely affect the country's GDP and the living standard of the population. Hence, if no intervention is taken, the change in the climate is expected to shrink the country's economy by $2.5 \%$ per year by $2050 .{ }^{[37]}$ Shifting to a more sustainable consumption and production path is the nucleus for attaining sustainable development and its realization demands the intervention of all stakeholders including international community. ${ }^{[43]}$ SCP is the heart of all other UNSDGs. According to Dereje et al ${ }^{[42]}$ though numerous companies are showing an effort in practicing green marketing, its successful implementations demands addressing a number of bottlenecks. The major challenge of green marketing is lack of consumer awareness regarding the environmental threat of their consumption. Sustainable production involves the manufacturing of eco-friendly products and services, the use of environmental friendly technologies and green power which requires huge investment on research and development activities and promotional campaign which in turn results in increased costs. Obviously, companies at the initial stage will not generate a profit due to high investment cost. Persuading customers to use green products is another challenge; however, this can be tackled by designing eco-label program. Since recyclable and renewable products are costly, customers may resist in welcoming green products. The government of Ethiopia should work meticulously in finding the right mechanism to diminish the undesirable impact of climate change, invest on adapting new technologies that can mitigate environmental disaster and launch afforestation and reforestation schemes. FDRE report ${ }^{[22]}$ reveals that, of the total GHG emissions, the contribution of agriculture and forestry accounts more than 85 percent whereas power, transport, industry and buildings contribute to the remaining percentage. Thus, improving the agriculture sector practice, transforming source of energy from eco-unsound to renewable sources and utilizing enhanced and innovative power saving technologies should be in place to achieve the Ethiopia's sustainable development goal. Particularly, the agriculture sector -- as the prime contributor of $\mathrm{CO} 2$ emission, necessitates vast improvement this includes but not limited to concentrating on mechanized farming, extending irrigation at large, medium and small scale, commencing eco-friendly technologies, introducing new seeds and breeds, decreasing expansion of farmlands, enlarging production efficiency and reducing emissions are some of them. As highlighted by UNEP ${ }^{[5]}$ dematerialization, consumption optimization, life-cycle management, product/service coordination, education and training and investment and insurance, corporate environmental responsibility and reporting are basic instruments to mitigate the problem of climate change and to promote SCP.

Shifting government's expenditure away from actions that jeopardize environmental capital, successful enforcement of policies and legislations, giving much emphasize to green economy via research, science training and awareness campaigns, amending resource and land possession rights, launching favorable atmosphere for community's behavioral change and instigating business organizations to incorporate sustainability issues in their program are identified as six national green growth enabling circumstances. ${ }^{[4]}$ Appropriate and organized system and resource deployment strategy should be in place to enhance Ethiopia's environmental condition.

\section{Reference}

[1] Hopwood, B., Mellor, M. and O’Brien, G. (2005) 'Sustainable development: mapping different approaches', Sustainable Development, Vol. 13, No. 1, pp.38-52.

[2] Graedel, T.E., Allwood, J., Birat, J.P., Buchert, M., Hagelüken, C., Reck, B.K. and Sonnemann, G. (2011) 'What do we know about metal recycling rates?', Journal of Industrial Ecology, Vol. 15, No. 3, pp.355-366.

[3] Ethiopian Environment Research Institute (2017), Federal Democratic Republic of Ethiopia, Country

\footnotetext{
${ }^{1}$ UNCSD submission, Jamaica (2012), Available at: http://www.uncsd2012.org/rio20/index.php?page=view\&type=510\&nr=566\&menu=20
} Accessed on [07/06/2018] 
Environment Analysis (CEA), Ethiopia Realizing Green Transformation

[4] Ethiopia, Central Statistical Agency (2012). Statistical Report on the 2012 Urban Employment-Unemployment Survey. Addis Ababa.

[5] United Nations Environment Programme UNEP (2011), Sustainable Consumption and Production in Africa, Nairobi, Kenya

[6] Aman, A. H. L., Harun, A., \& Hussein, Z. (2012). The influence of environmental knowledge and concern on green purchase intention the role of attitude as a mediating variable. British Journal of Art and Social Sciences, 7 (2), 145 - 167.

[7] Chartres, C.J. and Noble, A. (2015) 'Sustainable intensification: overcoming land and water constraints on food production', Food Security, Vol. 7, No. 2, pp.235-245.

[8] Brown, H.S. and P.J. Vergragt (208) (forthcoming), 'From consumerism to wellbeing: towards a cultural transition?'

[9] Brundtland, G.H., Khalid, M. (1987), "Our common future" Journal of Cleaner Production. WCED Oxford University Press, United Kingdom.

[10] World Business Council for Sustainable Development (WBCSD) (2012), a vision for sustainable consumption Innovation, collaboration, and the management of choice.

[11] Yared B., (2009) Environmental Problems and Solutions In Ethiopia Generally and In Africa Specifically, Jimma University, Faculty of Law

[12] Jain, S.K. and Kaur, G. (2004) 'Green marketing: an Indian perspective’, Decision, Vol. 31, No. 2, pp.168209.

[13]UN Commission on Sustainable Development, (UNCSD) (1995). InternationalWork Programme on Sustainable Consumption and Production Patterns United Nations. UN Commission on Sustainable Development, New York.Dereje \& Prasada (2015)

[14] Lebel, L. and S. Lorek (2008), 'Enabling sustainable production-consumption systems', Annual Review of Environment and Resources, 33, 241-275.

[15] Jackson, T. (2009), Prosperity without Growth: Economics for a Finite Planet, London: Earthscan.

[16] Veleva and Ellenbecker, 2001; Lowell Center for Sustainable Production, 1998; Routroy and Kumar (2016)

[17] Lawrence H., Peter C. and Sarita N., (2010), Complimentary article reprint, A Roadmap For Sustainable Consumption, Deloitte Touche Tohmatsu

[18] World Economic Forum and Deloitte Touche Tohmatsu (2010) Redesigning business value: a roadmap for sustainable consumption

[19] Sylvia L. and Philip J. (2016), Sustainable consumption as a systemic challenge: inter-and trans-disciplinary research and research questions

[20] Jennings, P.D. and Zandbergen, P.A. (1995) 'ecologically sustainable organizations: an institutional approach', Academy of Management Review, Vol. 20, No. 4, pp.1015-1052.

[21] UNEP (2012) Indicators for a Resource Efficient and Green Asia, paper under UNEP managed SWITCHAsia Regional Policy Support component, co-authored by Heinz Schandl, CSIRO and Anthony Chiu, De la Salle University

[22] Federal Democratic Republic of Ethiopia (FDRE) (2011), Ethiopia's Climate-Resilient Green Economy Green economy strategy

[23] United Nations Economic Commission for Africa (UNECA) (2015), Inclusive green economy policies and structural transformation in Ethiopia

[24]ADB (Asian Development Bank) (2012), Green Growth, Resources and Resilience - Environmental Sustainability in Asia and the Pacific, Manila.

[25] Knight, Kyle W. and Rosa, Eugene A. (2011). “The environmental efficiency of well-being: a cross-national analysis." Social Science Research 4 (3): 931-949.

[26] Ministry of Environment, Forest and Climate Change, Ethiopia (MEFCC) (2017), Available at http://mefcc.gov.et/about-us/, Accessed on [07/06/2018]

[27]UNDP Ethiopia (2018)

Available

at http://www.et.undp.org/content/ethiopia/en/home/presscenter/pressreleases/2017/02/22/ethiopia-launchesnew-sustainable-intervention-for-green-cities-development-.html Accessed on [15/06/2018]

[28]All Africa (2018), The Ethiopian Herald, Ethiopia: Country's Green Economy - Making Sustainable Development a Reality, Available at: https://allafrica.com/stories/201506250731.html Accessed on $[15 / 06 / 2018]$

[29] Tesfagebriel T. (2018) Implementation of Ethiopia's Green Economy Strategy: an example to learn from Available at: https://www.awrambatimes.com/?p=16572 Accessed on [17/06/2018]

[30]UNCSD submission, Jamaica (2012), Available at: http://www.uncsd2012.org/rio20/index.php?page=view\&type=510\&nr=566\&menu=20 Accessed on [07/06/2018] 
[31] Economic Commission for Africa (2015). Achieving sustainable Development in Africa through Inclusive Green Growth. Agriculture, Ecosystems, Energy, Industry and Trade. The Sustainable Development Report on Africa. Fifth Edition.

[32] World Economic Forum and Deloitte Touche Tohmatsu (2010) Redesigning business value: a roadmap for sustainable consumption

[33] Das, A. (2011) 'Farmers' suicide in India: implications for public mental health', International Journal of Social Psychiatry, Vol. 57, No. 1, pp.21-29.

[34] Barber, J., 2007. Mapping the movement to achieve sustainable production and consumption in North America. Journal of Cleaner Production 15 (6), 499e512.Primer (2011).

[35] IEA (International Energy Agency) (2010), Energy Poverty - How to make modern energy access universal?, IEA/OECD, Paris.

[36] Tukker et al., 2008; Collins et al., 2006; Huppes et al., 2006; Nijdam et al., 2005; Harris, 2005; Stevens, 2010; Kersten et al., 2015)

[37] World Bank (2011), Forest Carbon Partnership Facility Readiness Fund. Common Approach to environmental and Social Safeguards for Multiple Delivery Partners. Washington D.C.

[38] David Allaway and Leslie Kochan (2012) Literature Review: Key Challenges in Sustainable Consumption

[39] African Development Bank - Organization for Economic Cooperation and Development (2013). Enabling Green Growth in Africa: A joint report from the workshop held in Lusaka in Jan-15-16, 2013.

[40] Daniel K. (2008), Impacts of climate change on Ethiopia: A review of the literature, In Green Forum, Climate change-a burning issue for Ethiopia: Proceedings of the $22^{\text {nd }}$

[41] Dereje F. and Prasada R. (2015) Green Marketing and Green Growth as Path way towards Ethiopian Green Economy, International Journal of Academic Research

[42] Satterthwaite (2011), How urban societies can adapt to resource shortage and climate change, Philosophical Transactions of the Royal Society A: Mathematical, Physical and Engineering Sciences, Vol. 369, No. 1942, pp. $1762-1783$

[43] African Union Commission (2014).The Future We Want for Africa: Shared Strategic Framework for Inclusive Growth and Sustainable Development and a Global Strategy to Optimize the Use of Africa's Resources for the Benefit of all Africans, DRAFT Framework.

[44]Economic Commission for Africa (2012). Sustainable Development Report on Africa. Sustainable Consumption and Production (SCP) for Sustainable Growth and Poverty Reduction. 